\title{
ON THE INSUFFICIENCY OF TASTE EXPRESSIVISM**
}

\begin{abstract}
It is possible to construct situations (with a suitable kind of setting) in which one speaker utters "This is tasty" and another one responds with "That's not true." The aim of this paper is to motivate the idea that typical (broadly) expressivist accounts of taste disagreements are unable to explain such situations (although some of them can successfully explain disagreements in which another kind of dissent phrase - like "Nuh-uh" - is employed). This is because utterances of "That's not true" are typically used to ascribe falsehood to propositions. Taste expressivism has it, however, that when one utters "This is tasty," one typically manifests her evaluative attitude (which is non-propositional) toward something rather than describes what attitude she bears toward that thing. Another aim of the paper consists in proposing an alternative account of taste disagreements. It is close to taste expressivism in the case of disagreements in which speakers respond with "Nuh-uh" but departs from it in situations in which they respond with "That's not true." The account is developed within a contextualist framework according to which taste utterances express contextually enriched propositions that contain judges who evaluate things as tasty or not.
\end{abstract}

Keywords: contextualism, doxastic disagreement, evaluative attitude, non-doxastic disagreement, taste expressivism

Utterances of certain sentences about matters of personal taste (e.g., "This is tasty") seem to pose a challenge to theories according to which utterances of indicative sentences express propositions that are either true or false relative to how things are in the world of evaluation..$^{1}$ It is sometimes claimed, how-

* Department of Logic and Methodology of Sciences, Faculty of Arts, Comenius University in Bratislava, Šafárikovo námestie 6, P.O. BOX 440, 81499 Bratislava 1, Slovakia, e-mail: marian.zouhar@uniba.sk, ORCID: https://orcid.org/oooo-ooo3-2455-8722.

** This paper was supported by VEGA grant No. 1/oo36/17. I am indebted to anonymous reviewers for Filozofia Nauki for their criticisms and useful suggestions.

${ }^{1}$ I often use comprised expressions like "taste predicate," "taste sentence," "taste utterance," and "taste disagreement" instead of more prolix phrases like "predicate of personal taste," "sentence that contains a predicate of personal taste," "utterance of a sentence that contains a predicate of personal taste," and "disagreement about matters of personal taste." 
ever, that there are no objective facts that would make taste utterances true or false, but they are rather supposed to express non-propositional content. Different theories provide different explanations of what this kind of content is: they invoke affections or evaluative mental states, or evaluative attitudes toward something, to name just a few notable examples. When one utters "This is tasty," instead of expressing a proposition that the thing designated by "this" instantiates the property expressed by "is tasty," one expresses a content that consists in one's manifestation of one's positive evaluative (non-doxastic) attitude toward, or affection for, the thing in question. This approach can be labeled taste expressivism, since it is akin to expressivist approaches developed for some other kinds of discourse (most notably, moral discourse). ${ }^{2}$

Taste expressivism is sometimes invoked to explain taste disagreements. When one speaker utters "This is tasty," and another responds with "No, it is not," they obviously disagree. According to taste expressivism, they disagree in the sense of manifesting evaluative attitudes, which are usually characterized as non-cotenable, rather than expressing incompatible propositions. 3 I aim to show that this cannot be the whole story regarding taste utterances and their content. The very phenomenon of taste disagreements is rather multifaceted, and that is why the invocation of evaluative attitudes does not seem to suffice. To show this, I am going to discuss the effects of dissent phrases on communicative purposes of taste disputes.

\footnotetext{
${ }^{2}$ The term "taste expressivism" is used rather broadly in this paper. It covers both views that are expressivist in the proper sense and views that are hybrid in invoking nonexpressivist resources over and above expressivist ones. For taste expressivism, broadly conceived, cf. Buekens 2011, Clapp 2015, Gutzmann 2016, Huvenes 2012, and partially also Egan 2014 and Marques, García-Carpintero 2014. Taste expressivism is inspired by noncognitivist approaches to moral discourse, which have a more distinguished tradition, cf. Barker 2000, Boisvert 2008, Copp 2001, Eriksson 2014, Finlay 2005, Fletcher 2014, Ridge 2009, Strandberg 2012, to name just a few current representatives. Cf. also Schroeder 2010 for a very lucid exposition of non-cognitivism in ethics. Taste expressivism has it that the semantic content of taste utterances is - at least partially - non-cognitivist. According to other approaches, which include relativism and contextualism, taste utterances express full-blooded propositions. For relativism, cf. Kölbel 2002, Lasersohn 2005, MacFarlane 2014, Richard 2008, and Wright 1992; for contextualism, cf. Glanzberg 2007, López de Sa 2008, Marques, García-Carpintero 2014, Recanati 2007, Schaffer 2011, Silk 2016, and Zouhar 2018. Cf. Zeman 2016 for some criticism of contextualism.

3 The idea of non-cotenable attitudes is used to explain the sense in which attitudes can be incompatible. Adopting MacFarlane's formulation, two attitudes are non-cotenable when a rational judge who bears one attitude toward something cannot bear the other attitude toward the same thing without changing her mind (MacFarlane 2014: 121). For extensive evidence that disagreements need not consist in adopting incompatible propositions, cf. Silk 2016.
} 
The paper is structured as follows. I start by outlining a challenge to taste expressivism posed by some dissent phrases (Section 1). Then I discuss three taste expressivist accounts and apply them to the problematic kind of taste disputes. The accounts are found wanting in some respect or other (Section 2). An alternative proposal is outlined. It both meets the challenge and explains the expressivist observation that taste disagreements often arise at the evaluative (non-doxastic) level (Section 3). A brief summary concludes the paper.

\section{DISSENT PHRASES AND DISAGREEMENT}

When one responds to an utterance with a dissent phrase, one intends to express her disagreement. Typical dissent phrases include "No," "Nuh-uh," "I disagree," "I am of a different mind," "That is not true," etc. If used to respond to taste utterances, various dissent phrases may give rise to a number of different communicative effects. Semantic theories should be rich enough to cope with all such effects. I am going to argue that taste expressivism is not in a position to meet this demand.

To begin with, let us consider the effects of using "Nuh-uh" as a response to an utterance of an explicitly judge-relativized taste sentence.4 It is uncontroversial - even for taste expressivism - that such utterances express fullblooded propositions that are either true or false with respect to how things are with someone's tastes in a world of evaluation. Consider the dialogue in (1) ("Choco" names a particular chocolate cake):

(1)

$A$. Choco tastes good to me.

B. Nuh-uh. It does not taste good to me.5

\footnotetext{
${ }^{4}$ Sentences such as "This is tasty for me," "This tastes good to me," "This is among the foods whose flavor I like," etc. are labeled explicitly judge-relativized taste sentences because they contain explicit indexicals to designate judges. By contrast, "This is tasty" and similar taste sentences are not explicitly judge-relativized. They are simply referred to as taste sentences in this paper.

5 I admit that (1) and other dialogues used as examples in this paper may appear somewhat artificial (actually, this holds for many toy dialogues used in the literature on this topic). That is unimportant, though. If one would like to have dialogues that are closer to real-life exchanges, one may embellish the examples at will. For instance, one such dialogue (together with its setting) may run as follows:

$A$ and $B$ come at a cake-lovers party. $A$ immediately spots a table full of cakes and desserts.
} 
$A$ 's utterance expresses the proposition that Choco tastes good to $A$ and B's utterance of "It does not taste good to me" expresses the proposition that Choco does not taste good to B. Both of them thus explicitly describe their respective attitudes toward the cake's flavor. ${ }^{6}$

It seems to me that the following depiction of what is going on in the dialogue must be on the right track. $A$ reveals her evaluative attitude toward the cake by describing it; she suggests that her attitude is that of liking the cake's flavor. B's initial response with "Nuh-uh" can be understood in several ways, depending on what is the intended target of his utterance. It manifests either his rejection to take the same attitude as $A$ or his adoption of a particular attitude toward the cake's flavor. It is also plausible that $B$ does both things at the same time. For the sake of convenience, I assume the last option in this paper. $B$ further utters "It does not taste good to me." In so doing, he describes the attitude he adopts toward the cake's flavor - namely, the attitude of disliking. His response is thus rather complex and contains both the manifestation of an attitude and the description of an attitude. In both cases, he disagrees with $A$ by adopting an attitude that can be characterized as noncotenable with $A$ 's. This constitutes the core of their disagreement.

Now, it is important to realize that $B$ 's response in this situation consists merely in a manifestation and description of an evaluative attitude. In particular, he cannot be understood as rejecting $A$ 's proposition - that is, as suggesting that $A$ is speaking falsely. Similarly, $B$ needs not be understood as protesting against $A$ 's having her attitude: it is easy to imagine that $B$ in fact tolerates that $A$ has her attitude, yet he presents his own non-cotenable attitude.

A. "Look at those cakes over there! Let's try them all!"

$B$. "I agree. They look delicious."

Both $A$ and $B$ try some cakes but look rather disappointed. $A$ then turns to Choco.

$A$. "Yum! Choco tastes really good to me. I'll have more of it."

$B$. "Really? Let me try."

A few seconds later, he goes on:

B. "Nuh-uh. That's disgusting! It tastes like diabetes to me."

The embellishments aside, the dialogue in (1) can be said to capture the gist of $A$ 's second and $B$ 's third line in the above exchange. From the semantic point of view, an analysis of the abbreviated dialogue suffices for the purposes of this paper. That is why I am content with analyzing the artificial dialogues, while bearing in mind that they are just replacements of more vivid exchanges.

${ }^{6}$ I differentiate between describing one's evaluative attitude toward something and manifesting one's evaluative attitude toward something. In describing, one makes clear what kind of attitude one bears toward something by expressing a proposition in which one is related to the thing in question by that attitude. In manifesting, one performs a speech act and, by the very performance of the speech act, one makes her attitude apparent. 
Let us consider a dialogue in which $B$ responds a bit differently:

(2)

$A$. Choco tastes good to me.

$B$. That's not true. You looked a bit dissatisfied when swallowing it.7

As in the previous dialogue, $A$ makes plain her attitude toward the cake by way of expressing the proposition that Choco tastes good to $A$. B's response "That's not true" must be understood as saying that $A$ 's proposition is false. $B$ 's continuation with "You looked a bit dissatisfied when swallowing it" refers to a piece of evidence - namely, $A$ 's facial expression that $B$ uses to back up his previous claim. In other words, the point of $B$ 's utterance is to accuse $A$ of not being honest about her attitude toward the cake.

Importantly, in saying "That's not true," $B$ merely presents his view about $A$ 's proposition and nothing else. His utterance cannot be understood as presenting his own view on Choco's flavor; $B$ 's attitude toward Choco is in fact irrelevant to his assessment of $A$ 's utterance as true or false.

The difference between (1) and (2) suggests that "Nuh-uh" and "That's not true" are instances of different types of dissent phrases that can be used to achieve different communicative effects - namely, different kinds of disagreement. The main contrast is that if one responds to a taste utterance by using "That's not true," one intends to express something about the truthevaluable content of the utterance - namely, assess it as false - while if one responds to a taste utterance by using "Nuh-uh," one may intend to comment on what was expressed at some other level of the content. In other words, "That's not true" is used to present doxastic disagreement with some proposition, while "Nuh-uh" is usually used to present non-doxastic disagreement with some evaluative attitude. ${ }^{8}$

\footnotetext{
${ }_{7}$ Again, (2) is a digest of a more sophisticated exchange set in suitable circumstances. For example:

$B$ hosts a party at which he serves his home-made cakes, and $A$ attends the party. $B$ is interested in what cakes $A$ finds tasty. like?”

$B$. "Will you try those cakes over there and tell me which flavors are among those you

A. "By all means! But you should know that I'm choosy about cakes."

$A$ tries some cakes and announces her favorable verdicts about each. Finally, she tries

Choco and finds its flavor rather unappetizing. Inadvertently she frowns a bit. Nevertheless, she wants to be polite to the host and opts for a harmless lie.

A. "Yum! This one also tastes good to me."

$B$. "That's very nice of you. But I guess that's not quite true. You looked a bit dissatisfied when swallowing it."

${ }^{8}$ I admit that there are situations in which "Nuh-uh" is also used to express doxastic disagreements. The difference between "That's not true" and "Nuh-uh" consists in that the
} 
The fact that various dissent phrases can be used to achieve different effects may cause some troubles for taste expressivism. According to taste expressivism, the chief purpose of taste utterances (that are not explicitly judgerelativized) is to manifest one's evaluative attitude rather than describe what attitude one bears; when one utters "Choco is tasty," instead of attributing a full-blooded property to the cake, one manifests a positive evaluative attitude toward it.

Take the following dialogue:

A. Choco is tasty.

B. Nuh-uh. It is not. 9

Taste expressivism seems to have a satisfactory explanation. In uttering "Choco is tasty," $A$ manifests her non-doxastic attitude and, in responding "Nuh-uh, it is not," $B$ disagrees with $A$. In particular, the utterance of "Nuh-uh" manifests both $B$ 's refusal to take the same attitude as $A$ and $B$ 's adoption of a certain attitude toward the cake's flavor that can be characterized as noncotenable. Furthermore, according to some versions of taste expressivism, the content of $A$ 's utterance of "It is not" is non-propositional and merely consists in the manifestation of an evaluative attitude. According to some other versions, $A$ 's utterance has both a propositional and a non-propositional kind of content; nevertheless, it is the latter content that is relevant to $A$ 's communicative intentions. Accordingly, $B$ 's disagreement does not consist in a rejection of whatever proposition (if any) $A$ would have succeeded in expressing by her utterance; rather, $B$ makes explicit his refusal to adopt the same evaluative attitude toward Choco as $A$ and his adoption of an attitude that is non-cotenable with $A$ 's. Admittedly, this is essentially what happens in situations in which the exchange contained in (3) occurs.

Now, it seems to me that this kind of explanation cannot be applied to (4), however:

A. Choco is tasty.

$B$. That's not true. You looked a bit dissatisfied when swallowing it. ${ }^{10}$

former is always used to express doxastic disagreement while the latter - being a standard vehicle for non-doxastic disagreement - expresses it only sometimes. I am indebted to an anonymous reviewer for this clarification.

9 One may imagine that (3) is an extract of a modified version of the dialogue presented in footnote 5 , in which $A$ 's second line is replaced with the following: "Yum! Choco is really tasty. I'll have more of it." 
As in (2), $B$ is best understood as accusing $A$ of not being honest about her attitude toward the cake's flavor. $B$ 's use of "that" is anaphorically dependent on a previous piece of discourse - namely, $A$ 's utterance - and says that what it expresses is not true. $B$ thus suggests that $A$ 's utterance is untrue and refers to a piece of evidence he has at his disposal - namely, $A$ 's facial expression. Notice that in saying "That's not true" $B$ merely presents his view about $A$ 's proposition and nothing else. He says that $A$ said something false because the content of her claim did not cohere with her "body language." $B$ 's utterance cannot be understood as presenting his own view on Choco's flavor; in fact, $B$ 's attitude toward Choco is irrelevant to his evaluation of $A$ 's utterance as true or false. ${ }^{11}$

As in the case of (1) and (2), the difference between (3) and (4) can be summarized by saying that while the disagreement in (3) can be plausibly treated as non-doxastic, the disagreement in (4) cannot but be classed as doxastic. It seems to me that taste expressivism is not in a position to handle satisfactorily the latter exchange. I am going to show in the next section that this holds not only for the expressivist theories that assign only a nonpropositional kind of content to taste utterance but also for those that assign both propositional and non-propositional content to them.

It is worth noting that there is an important difference between the dialogues in (1) and (3), on the one hand, and those in (2) and (4), on the other. (1) and (3) may occur in situations in which competent speakers have the intuition that the disagreement between $A$ and $B$ is faultless, while the latter dialogues do not permit such situations. The above comments on each dialogue suggest that this can be so. The speakers in (2) and (4) accept incompatible propositions, in which case either $A$ or $B$ misses the truth (lies or makes a mistake); their disagreement cannot thus be faultless. For example, in (2), $A$ expresses the proposition that Choco tastes good to $A$, and $B$ responds by denying this proposition; thus one of them must be saying something false. By contrast, the speakers in (1) and (3) express non-cotenable attitudes, and both of them can do so without making any mistake; their disagreement can thus be faultless. A correct explanation should do justice to these intuitions.

\footnotetext{
${ }^{10}$ The dialogue in (4) might strike one as problematic. However, it does make sense in an appropriate setting. One may imagine that (4) is an extract of a modified version of the dialogue presented in footnote 7. The modification consists in the replacement of $A$ 's second line with the following: "Yum! This one is tasty too."

${ }^{11}$ An analogous line of argumentation can be developed using propositional attitude verbs. Suppose that $B$ responds to $A$ 's utterance of "Choco is tasty" with "I don't believe you. You looked a bit dissatisfied when swallowing it." $B$ is clearly related to a proposition in his response. He suggests that he disbelieves the proposition expressed by $A$ 's utterance, which means that he takes for granted that $A$ 's utterance does express a proposition.
} 


\section{SOME TASTE EXPRESSIVISTS}

The above discussion of (3) and (4) was cast in general terms. It would, however, be appropriate to consider particular taste-expressivist theories and their prospects for satisfactory explanations of the dialogues. I am going to discuss three such accounts. In 2.1, I focus on a theory according to which the content of taste utterances is merely non-doxastic; in 2.2 and 2.3, I consider two theories that assign both propositional and non-propositional contents to taste utterances.

\subsection{CLAPP}

Lenny Clapp presents a non-alethic approach to taste disagreement that he himself labels "broadly expressivist" (Clapp 2015: 518). According to his theory, when $A$ utters "Choco is tasty," she (i) fails to express any proper proposition that can be either true or false and (ii) pragmatically expresses a mental state she finds herself in upon trying Choco (Clapp 2015: 513) or an evaluative attitude of liking Choco's flavor (Clapp 2015: 531). These are particular instances of what Clapp calls the negative semantic thesis and the positive pragmatic thesis, respectively (Clapp 2015: 531). Regarding the former, taste predicates do not "semantically determine a complete intension," i.e., their semantics underdetermines their extension relative to possible worlds (Clapp 2015: 533). On the other hand, they do contribute somehow to the semantics of taste sentences; as a result, taste sentences, despite having no "metaphysical truth conditions," have "mere semantic truth conditions" (Clapp 2015: 534). This amounts to saying that, upon encountering an utterance of "Choco is tasty," a person knows that it would be true provided Choco were in the extension of "is tasty"; the problem is, however, that there is no metaphysical fact of the matter that would consist in Choco's membership in such a set.

Clapp's explanation of what is going on in (3) is based on a Stalnakerian theory of conversation according to which participants of a discussion attempt to modify the common ground of the discussion that comprises both a doxastic set and an evaluative set (Clapp 2015: 538-540). A's utterance is used to pragmatically express the evaluative mental state of liking Choco's flavor, thereby $A$ intends to modify the common ground by adding the state of liking Choco's flavor to the evaluative set. B's disagreement, roughly, consists in two things: by uttering "It is not (tasty)," he intends to remove the mental state of liking Choco's flavor from the evaluative set and add the state 
of not liking it in its stead. Consequently, $B$ 's disagreement is non-doxastic. It should be added that what both $A$ and $B$ do also influences the doxastic set: $A$ suggests enriching it with the doxastic state of believing that Choco is tasty, and $B$ suggests otherwise. It is worth noting that the contents of those beliefs are not complete propositions, and so the non-doxastic aspect of disagreement prevails over the doxastic one (Clapp 2015: 539). Thus, $B$ primarily disagrees with $A$ in the non-doxastic sense.

Now, what does Clapp have to say about (4)? B's disagreement with $A$ in (4) is doxastic rather than non-doxastic. B's communicative intention does not consist in manifesting his own evaluative attitude toward Choco's flavor, but rather in accusing $A$ of speaking falsely, i.e., of expressing a content that is false. The manifestation of evaluative attitudes is neither true nor false, and thus of no use with respect to (4). Since there are no metaphysical truth conditions A's utterance would depict, the best reply Clapp might provide invokes the notion of semantic truth conditions. Based on this, $B$ 's response "That's not true" might be understood as saying that the semantic truth conditions of $A$ 's utterance do not obtain, which means that they are false. This reply is actually modelled on Clapp's own treatment of the Frege-Geach problem (Clapp 2015: 534-536). He says that his broadly expressivist approach is immune to this difficulty, since utterances of taste sentences, regardless of whether taken alone or as embedded in larger constructions (like conditionals), are "in a sense, truth-apt" (Clapp 2015: 535). They are supposed to be truth-apt because they encode semantic truth conditions. Along the same lines, $A$ 's utterance of "Choco is tasty" is, in a sense, truth-apt, and that is why B's response "That's not true" seems to be a suitable kind of response.

Whatever the merits of this response to the Frege-Geach problem, it strikes me as unsatisfactory when it comes to the exchange contained in (4). If $B$ utters "That's not true," his utterance of "that" has to be understood as designating the semantic truth conditions of $A$ 's utterance and presenting them as not obtaining, i.e., as false. This is problematic, though. Clapp admits that utterances of taste sentences are truth-apt because they encode semantic truth conditions. However, it is by no means clear how to make sense of the claim that taste utterances are both truth-apt and unable to be true or false (since they fail to express full-blooded propositions). Intuitively, the truthaptness of a semantic content amounts to the conceivability of a situation in which the semantic content is either true or false. In the case of $A$ 's utterance of "Choco is tasty," such a situation cannot arise if Clapp's negative semantic thesis is to be taken seriously. Thus, $B$ 's utterance of "That's not true" must be assessed as inappropriate by Clapp's lights. But this outcome conflicts with 
what we naturally expect if we take the exchange in (4) as acceptable. A way out for Clapp might consist in saying that (4) is not acceptable. This kind of defense is, however, hardly appealing given that it is possible to construct situations with appropriate setting in which the exchange in (4) does make sense.

In sum, Clapp's approach is unable to explain what the exchange contained in (4) amounts to, although it can explain the dialogue in (3). This is because (4) seems to make sense only if taste utterances are allowed to express fully-fledged propositions.

\subsection{GUTZMANN}

Daniel Gutzmann offers another broadly expressivist proposal regarding taste utterances (Gutzmann 2016). Unlike Clapp, however, he makes room for taste utterances to express full-blooded propositions that can be assessed as true or false. More precisely, taste utterances have two kinds of content namely, the truth-conditional content and "the use-conditional content" (Gutzmann 2016: 38-40). A's utterance of "Choco is tasty" expresses the contextually enriched proposition that Choco is tasty for $A$ as its truth-conditional content; the proposition is true in the world of the context of utterance provided that Choco is tasty for $A$. Since the truth-conditional content contains a particular judge, it is subjective. The utterance's use-conditional content consists in suggesting that Choco shall count as tasty in the context of utterance. This kind of content is normative because it states how people are recommended to respond to Choco's flavor (Gutzmann 2016: 41). The normative nature of the use-conditional content combines with the subjective truth-conditional content to make one's subjective claims about her own taste relevant from a broader perspective. Moreover, the contents are interconnected, which means that $A$ would assert that Choco is tasty for her only if she believed that Choco was to count as tasty in that context (Gutzmann 2016: 43).

Given this framework, the disagreement contained in (3) is easily explained. Both $A$ and $B$ express propositions about their respective tastes; the propositions are perfectly compatible because one portrays Choco as tasty for $A$ and the other as not tasty for $B$. Yet, despite being compatible, they suggest incompatible normative attitudes toward Choco: $A$ 's proposition suggests that Choco is to be counted as tasty and $B$ 's proposition suggests otherwise. The disagreement between $A$ and $B$ thus concerns the normative useconditional contents.

What does Gutzmann's proposal permit one to say about the exchange contained in (4)? B's utterance of "That's not true" definitely makes good 
sense, because $A$ 's utterance of "Choco is tasty" expresses a proposition. Gutzmann may thus claim that $B$ simply rejects $A$ 's proposition, meaning that, according to $B$, it is not the case that Choco is tasty for $A$. Furthermore, Gutzmann suggests that the truth-conditional content of an utterance is interrelated with its use-conditional content. Consequently, if $B$ utters "That's not true," he succeeds not just in rejecting the truth-conditional content of $A$ 's utterance but, in doing so, also succeeds in undermining what its useconditional content amounts to. Assuming that a taste utterance can be either true or false with respect to its truth-conditions and either felicitous or infelicitous with respect to its use-conditions (Gutzmann 2016: 36-37), by uttering "That's not true" $B$ suggests that $A$ 's utterance of "Choco is tasty" is both false and infelicitous.

Upon closer scrutiny, however, it can be shown that this explanation, though possibly successful with respect to (4), fails as a general account. It seems to me that the use-conditional content cannot be linked with the truthconditional content in the above way. This is because there might be situations in which one intends to reject the truth-conditional content of a speaker's taste utterance but retain its use-conditional content.

For example, if $B$ knew that $A$ was insincere upon asserting "Choco is tasty," he might point to her insincerity by saying that what $A$ said was false. Nevertheless, $B$ might wish to stick to the normative content of $A$ 's utterance. The following exchange should be acceptable if $A$ 's utterance were to express the proposition that Choco is tasty for $A$ :

\section{A. Choco is tasty.}

$B$. You are not speaking truly, because you obviously dislike the cake. Anyway, people should definitely consider it tasty. In fact, I find it delicious.

In his response "You are not speaking truly because you obviously dislike the cake," $B$ has to be taken merely as rejecting $A$ 's truth-conditional content. If he also rejected her use-conditional content, it would be inconsistent for him to continue with "Anyway, people should definitely consider it tasty." Intuitively, however, $B$ 's response, taken as a whole, does not suffer from any inconsistency. Thus, "You are not speaking truly" should be understood as rejecting merely the truth-conditional content of $A$ 's utterance. Now, this would not be possible if the infelicity of normative contents of taste utterances were linked to the falsity of their truth-conditional contents, as Gutzmann's theory required. If the proposal according to which taste utterances have both the 
truth-conditional content and the use-conditional content is to be sufficiently general, it should keep the two kinds of content separate. ${ }^{12}$

$$
\text { 2.3. BUEKENS }
$$

Filip Buekens developed another type of broadly expressivist proposal namely, a version of speech act approach enriched with certain expressivist ideas (Buekens 2011). Like Gutzmann, he accepts that taste utterances express propositions that are either true or false. Buekens distinguishes between two aspects of taste utterances - namely, the assertive dimension and the affective-expressive dimension. Regarding the former, taste utterances express contextually enriched propositions that contain judges as their constituents: relative to the context of utterance, $A$ 's utterance of "Choco is tasty" expresses the proposition that Choco is tasty for A. However, the point of making the utterance is not confined to expressing the proposition about $A$ 's attitude toward Choco's flavor. It primarily consists in manifesting $A$ 's affection toward the cake; this is the core of its affective-expressive dimension. Manifesting one's attitude is different from, and irreducible to, saying that one takes the attitude (Buekens 2011: 639). Regarding the expressiveaffective dimension, two things are worth noting. First, it is independent of the other dimension, because it does not accompany all uses of taste sentences; there are uses that carry the assertive dimension without carrying the affective-expressive dimension and there are uses that have both (Buekens 2011: 641). For example, the affective-expressive dimension is usually missing in exocentric uses (Buekens 2011: 649) but is present in many - though not all - autocentric uses. ${ }^{13}$ It is also missing in utterances of explicitly judgerelativized taste sentences (Buekens 2011: 646). Second, extending Kant's position regarding aesthetic judgments to taste utterances, Buekens claims that

${ }^{12}$ In any event, I doubt that taste utterances express normative contents besides their truth-conditional contents. If they do, the following kind of exchange would have to be acceptable:

A: Choco is tasty.

B: Yeah, you're right. I agree that people should like its flavor.

B's response is, however, inappropriate. Saying "I agree that people should like its flavor" (where the normative appeal is made explicit), so as to justify the "Yeah, you're right" part, appears to be off-topic. For this reason, it seems that there is no normative constituent in the content of A's taste utterance with which anyone might agree or disagree. This casts doubt on the idea that taste utterances in general contain a normative part in their contents.

${ }^{13}$ The notions of autocentric uses and exocentric uses are Lasersohn's, cf. Lasersohn 2005: 670 . 
the affective-expressive dimension, although connected with the speaker's subjective perspective, has a transcendent character in that it invites the intended audience to imagine having a similar experience with the thing in question (Buekens 2011: 652-654).

Given this framework, the dialogue contained in (3) amounts to the following: $A$ expresses the proposition that Choco is tasty for $A$ and manifests her affection toward the cake. $B$ 's response with "Nuh-uh, it is not" expresses the proposition that Choco is not tasty for $B$ and manifests his opposite affection. The sense of disagreement is due to the fact that $A$ speaks with "the universal voice" (Buekens 2011: 653), meaning that $A$ invites $B$ to empathize with her by liking Choco's flavor. $B$ rejects the invitation, thus refusing $A$ 's attempt at making a claim with a transcendent character.

Can this treatment be successfully applied to the exchange contained in (4)? A's utterance is used to manifest $A$ 's affection toward Choco's flavor and, due to its transcendent nature, invite $B$ to share the same affective-expressive attitude. When $B$ says "That's not true," he cannot be understood as undermining A's manifestation of her affection toward Choco's flavor, since affections cannot bear truth values. He also cannot be understood as responding to $A$ 's invitation because one usually does not reject invitations of any kind by suggesting that they are untrue - invitations are not a kind of thing that might be true or false. Nevertheless, $B$ 's response definitely makes sense because $A$ 's utterance expresses a truth-conditional content - namely, the proposition that Choco is tasty for $A$. $B$ thus suggests that this proposition is false and provides a piece of evidence by pointing to $A$ 's facial expression. (Incidentally, $B$ says nothing about his own evaluation of Choco's flavor; his utterance of "That's not true" is neither intended to express the proposition that Choco is not tasty for $B$ nor meant to manifest B's own affection toward Choco's flavor.)

Moreover, Buekens's proposal, unlike Gutzmann's, seems to be capable of handling the dialogue in (5). Since the affective-expressive dimension of utterances is independent of their assertive dimension, one might be able to reject one of them, leaving the other untouched. $B$ in (5) can be regarded as rejecting the truth-conditional content of $A$ 's utterance while accepting its use-conditional content, as his utterance of "Anyway, people should definitely consider it tasty" clearly indicates. Buekens's proposal may thus portray B's contribution to the dialogue as consistent. This is a welcome result.

These advantages notwithstanding, Buekens's account is open to criticism because the idea that the uses of taste sentences are transcendent in the above sense seems debatable. In particular, it is doubtful that when one utters a taste sentence one makes an invitation to share the same affectiveexpressive attitude. There are at least two reasons for this doubt. 
First, generally speaking, invitations can be made either by using sentences with an appropriate illocutionary force or by asserting suitable sentences with an appropriate verb as a substitute for the illocutionary force. For example, one may utter "Come and visit me" with an appropriate illocutionary force to invite someone to pay a visit to the speaker; one may also assert "I invite you to visit me" to the same effect. Now it seems awkward to say "Come and visit me. I invite you to visit me" in a single uninterrupted utterance. This is because the pair of uttered sentences, as they stand, are needlessly repetitive, which means that the latter sentence adds nothing new to the former. However, if one utters the following pair of sentences, no sense of inappropriateness is elicited (the second sentence is to be uttered with an illocutionary force that is appropriate to invitations):

Choco is tasty. Try it and have the same feelings about its flavor.

The second sentence of (6), when uttered with an appropriate illocutionary force, is an invitation for an addressee to join the speaker in her evaluation of Choco's flavor. Since the speaker's utterance of the second sentence does not merely repeat the point her utterance of the first sentence seems to make, the first sentence hardly makes an invitation. Similarly, consider the following utterance that seems to be acceptable:

Choco is tasty. I invite you to have the same feelings about its flavor.

The second sentence in (7) adds something new; and since it is used to make an explicit invitation, the first sentence cannot be a proper vehicle for an invitation.

Second, invitations can be either accepted or rejected. There are at least two general ways to do that - namely, to perform activities that are in accordance (or at odds) with the content of the invitation or to assert that one accepts (or rejects) it. For example, one may accept the invitation made by uttering "Come and visit me" (or "I invite you to visit me") either by performing activities that lead to visiting the speaker's house or by asserting "I accept your invitation." Both kinds of response are equal, and if one is in a position to accept an invitation in one way, one has to be in a position to do so in the other way too. Now, the dialogue in (8) is surely awkward:

\section{A. Choco is tasty.}

$B$. I accept/reject your invitation to have the same feelings about its flavor. 
The oddity of (8) suggests that it is inappropriate to respond to an utterance of a taste sentence by asserting that one accepts (or rejects) an invitation. By contrast, $B$ 's response in (9) is fine:

(9)

$A$. Choco is tasty.

$B$. Yes, it's tasty. (No, it isn't tasty.)

Since $B$ 's responses in (8) and (9) prompt different evaluations, the sentences such as "Choco is (not) tasty" do not seem to express invitations, and the responses such as "Yes, it's tasty" and "No, it isn't tasty" are not suitable vehicles for accepting or rejecting invitations.

We do not get a better result if B's acceptance or rejection of the transcendent aspect of $A$ 's utterance is cast in normative terms. This dialogue is awkward:

\section{A. Choco is tasty.}

$B$. I (dis)agree that we should consider it tasty. / I (dis)agree that it should taste good to us.

The infelicity of $B$ 's explicit (dis)agreement suggests that $A$ 's utterance is not transcendent in the above sense. Thus $A$ should not be portrayed as making a universal recommendation to adopt a certain kind of attitude toward Choco's flavor.

Interestingly, the following seems fine:

$$
\text { A. Choco is tasty. }
$$

\section{B. I (dis)agree. We should/shouldn't consider it tasty.}

$B$ 's response is felicitous because it is divided into two separate sentences that can be viewed as independent of each other. $B$ 's universal recommendation (contained in "We should/ shouldn't consider it tasty") is presented as detached from his (dis)agreement with $A$ 's claim. $B$ thus first expresses his (dis)agreement with $A$ and then adds a remark on which kind of attitude he recommends, thereby introducing a new issue into the debate. ${ }^{14}$

To conclude, Buekens's proposal, according to which the uses of taste sentences are transcendent in the above sense, is not satisfactory because

\footnotetext{
${ }^{14}$ Someone might argue that (10) is acceptable in some situations after all. It seems to me, however, that this can be so only in the situations in which $B$ intends not just to respond to what $A$ has expressed but also to extend the range of the dispute beyond the boundaries set by $A$ 's utterance. This is precisely what happened in (11). Thus, (10) might be acceptable if it is not taken at face value but understood along the lines similar to (11).
} 
taste utterances do not seem to convey invitations. Since the transcendent aspect of the uses is crucial to his treatment of taste disagreements, the explanation is not established on a firm basis. Based on this, the theory is not in a position to handle the dialogue in (3), although it seems acceptable in the case of the dialogue in (4). Regarding the latter, $B$ merely rejects the assertive content of $A$ 's utterance, in which case the alleged transcendent affectiveexpressive content is not invoked at all. Regarding the former, however, the transcendent kind of content is crucial because $B$ 's disagreement with $A$ is expressed in terms of rejecting $A$ 's invitation. If $A$ makes no invitation by her utterance of "Choco is tasty," $B$ 's denial calls for another kind of interpretation. Buekens's theory does not provide it. ${ }^{15}$

\section{A CONTEXTUALIST ALTERNATIVE}

I am going to propose an alternative explanation of disagreements exemplified by the exchanges in (3) and (4). It is based on a contextualist theory of taste utterances that shares some features with Buekens's and Gutzmann's approaches. Since its elaboration and defense is available elsewhere (see Zouhar 2018), I only summarize the main points. The core idea is that the content of taste utterances does not bifurcate, although they express contextually enriched taste propositions that conceptually entail propositions about non-doxastic attitudes. In this framework, it is possible to treat some kinds of taste disagreement as non-doxastic while some others as doxastic, which means that the framework is sufficiently rich to cope with a wide range of situations.

Taste utterances express contextually enriched propositions. Relative to different contexts of utterance, the same taste sentence can be used to express different taste propositions, depending on who is the judge in a given context. An utterance of "Choco is tasty" expresses the proposition that Choco is tasty for $A$ if $A$ is the judge and the proposition that Choco is tasty for $B$ if $B$ is the judge. These propositions can be further unpacked, because the attribute of tastiness is open to analysis. It seems plausible that something is tasty for a judge provided that the thing in question produces pleasant experiences of a certain sort and the judge generally welcomes having such experiences. Consequently, the proposition that Choco is tasty for $A$ can be unpacked as the proposition that Choco interacts with A's gustatory capacities

${ }^{15}$ I am grateful to an anonymous reviewer for a detailed discussion that led to a substantial revision of this section. 
in a way that produces agreeable gustatory experiences of an intrinsically desirable sort. 16

If something produced agreeable and desirable experiences of a certain sort, the judge would definitely like the thing. It would be unintelligible if something produced such experiences, but the judge disliked the thing. This suggests that there is a conceptual connection between the property of being tasty for A (i.e., the property of interacting with A's gustatory capacities in a way that produces agreeable gustatory experiences of an intrinsically desirable sort) and the property of having a flavor liked by A. ${ }^{17}$ This connection can be captured in terms of the requisite relation that represents a necessary connection between properties: property $R$ is a requisite of property $P$ if and only if, for all possible worlds $w$ and objects $y$, it holds that if $y$ instantiates $P$ at $w$, then $y$ also instantiates $R$ at $w .^{18}$ The property of having a flavor liked by $A$ is a requisite of the property of being tasty for $A$.

By way of illustration, it can be said that the relation between the properties of being tasty for $A$ and having a flavor liked by $A$ resembles the relation between the properties like being a philosopher and being human or being spherical and being three-dimensional. Whenever something is a philosopher, it also must be human, and whenever something is spherical, it also must be three-dimensional. In other words, nothing can be a philosopher without also being human, and nothing can be spherical without also being three-dimensional. Accordingly, whenever something is tasty for $A$, it also must have a flavor $A$ likes; i.e., nothing can be tasty for $A$ without having a flavor $A$ likes. Thus, if $A$ asserted "This is tasty (for me) but I don't like the flavor," she would assert something that could not be true.

Taking for granted that having a flavor liked by $A$ is a requisite of being tasty for $A$, the proposition that Choco is tasty for $A$ entails the proposition

16 This analysis draws on Andy Egan's (2010: 270). My analysis, however, departs from his in not being dispositional, cf. Zouhar 2018: 444-446. Taste attributes are dispositional also on some other accounts; cf. e.g. Clapp 2015 and Marques 2015.

${ }_{17}$ Natalia Karczewska suggests that the meaning of "tasty," which the speaker has in mind while uttering taste sentences, consists of "a number of dimensions (or components) bound by a certain algorithm thanks to which she decides whether a given sample of food is tasty or not" (Karczewska 2016: 36). This is clearly a different notion of tastiness than the one I invoke in the main text. I agree that judges usually decide whether something is tasty or not on the basis of how they assess the thing in question relative to what Karczewska labels "dimensions" (such as flavor, aroma, texture, etc.). However, I do not think that, on this basis, the dimensions should be directly involved in the meaning of taste predicates.

${ }^{18}$ This definition is a simplified version of the definition proposed in Duží, Jespersen, Materna 2010: 361. The notion of a requisite was introduced by Pavel Tichý (1979: 408). 
that Choco's flavor is liked by A. The latter proposition describes A's evaluative (non-doxastic) attitude toward Choco's flavor. This fact amounts to saying that when one utters a taste sentence, one also implies - by virtue of entailment - what her evaluative attitude toward the object in question is. It is uncontroversial that the role of a judge can be played by various individuals or groups of individuals; in some contexts, the judge is the same as the speaker and, in some other contexts, it can be someone else - an addressee, a group of people in which the speaker may, but need not, be a member, etc. Accordingly, a more general formulation would have it that if the speaker utters "Choco is tasty" while having a particular judge in mind, she implies - by virtue of entailment - that the judge adopted the evaluative attitude of liking Choco's flavor.

It should be clear how this explanation relates to the disagreement contained in dialogue (3). A's utterance expresses the proposition that Choco is tasty for $A$, and $B$ 's response "It is not (tasty)" expresses the proposition that Choco is not tasty for $B$. The former entails the proposition that Choco's flavor is liked by $A$, while the latter entails the proposition that Choco's flavor is not liked by $B$. Thus, $A$ portrays herself as taking a certain evaluative attitude toward the cake; recognizing her position, $B$ portrays himself as adopting a different attitude - namely, one that can be characterized as non-cotenable with $A$ 's. More precisely, $B$ first responds with "Nuh-uh" to manifest both his resistance to take the same attitude as $A$ and his adoption of a certain attitude toward the cake's flavor, and then continues with "It does not taste good to me" to describe the attitude of disliking he adopts toward the cake's flavor. In so doing, $B$ presents himself as disagreeing with $A$ because of the difference in their attitudes toward Choco. In other words, when $B$ says "Nuh-uh. It is not (tasty)," he rejects neither the proposition expressed by $A$ 's utterance nor the proposition entailed by it, but by asserting a proposition that entails a proposition in which a non-cotenable attitude is contained, $B$ rejects taking the same attitude as $A$ toward the cake. The disagreement in (3) is thus non-doxastic.

This explanation is in some respects rather close to the one proposed by taste expressivism; yet it is obtained in a manner that is non-expressivist at heart. According to expressivist theories, taste utterances express either an expressive (i.e., non-truth-conditional) content as their single kind of content or an expressive content supplemented with a truth-conditional kind of content. According to the present account, however, the content of taste utterances is merely truth-conditional, because they are supposed to express propositions that can be true or false and nothing else - there is thus no expressive kind of content to be expressed by taste utterances. Nevertheless, since by uttering taste sentences speakers express taste propositions that en- 
tail propositions about judges taking some evaluative attitude or other, we are in a position to explain taste disagreement phenomena in terms of the judges adopting non-cotenable non-doxastic attitudes. ${ }^{19}$

This explanation can be rather straightforwardly extended to the dialogue contained in (4). In (4), $B$ does not manifest his own views on Choco's flavor but merely claims that $A$ was not speaking truly. The content of $A$ 's utterance is the proposition that Choco is tasty for $A ; B$ thus suggests that this proposition is false (by saying "That's not true") and provides a piece of evidence (by saying "You looked a bit dissatisfied when swallowing it"). Since $A$ 's proposition entails the proposition that Choco's flavor is liked by A, B's denial of the former also results in rejecting the latter (together with any other consequences of the former proposition). $B$ thus implies - by virtue of entailment - that $A$ does not like Choco's flavor. $B$ 's disagreement with $A$ is purely doxastic. The account outlined above is thus able to do justice to the dialogue in (4). For this reason, it surpasses Clapp's theory.

Let us compare the effects of both dialogues. In both cases, $B$ eventually rejects $A$ 's evaluative attitude toward Choco's flavor, although the two rejections are substantially different. In (3), he uses a dissent phrase by which he makes plain the resistance to adopt the same evaluative attitude as $A$. Notice that in so doing $B$ may not object to $A$ 's having the evaluative attitude she implies she has. Yet he definitely refuses to adopt the same attitude himself, in which case he provides information about his own position regarding the cake. This kind of rejection on $B$ 's part results in embracing an evaluative attitude toward the thing under discussion, which is further strengthened by his utterance of "It is not tasty." $B$ thus non-doxastically disagrees with $A$. In (4), $B$ uses a dissent phrase that allows him to make plain his disbelief regarding what $A$ said. He thus directly objects to what she said by pointing to

${ }^{19}$ It might be argued that bearing non-cotenable (non-doxastic) attitudes toward the same thing may not suffice for the emergence of disagreement between agents (i.e., despite taking non-cotenable attitudes, the agents might not be portrayed as disagreeing with one another). An idea to this effect was presented, for example, in Marques 2015: 7. If this is correct, a completely satisfactory explanation of taste disagreements should be more complicated than the theory sketched here. I leave this issue aside, however, as it is secondary with respect to our discussion of the dialogues such as (4) and the communication effects that can be brought about by using "That's not true" and similar phrases in conversations about taste. Nevertheless, without going into details, I take it that the above idea, if true, would not require any substantial changes at the level of the semantic content of taste utterances. The worries regarding the insufficiency of non-cotenability can be handled at the level of communication pragmatics instead. Besides, in many cases, the mere noncotenability seems to suffice for explaining the emergence of disagreement between agents. I hope to elaborate on these points elsewhere. 
the falsity of her statement. That is, $B$ objects to $A$ 's having the evaluative attitude she implies she has. Notice that in so doing $B$ reveals nothing about his evaluative attitude (if any) toward the cake. This kind of rejection on $B$ 's part results in embracing a certain view about the proposition $A$ expressed. $B$ thus doxastically disagrees with $A$.

Besides, this account does justice to the idea that the situations in which the dialogue in (3) occurs may comprise disagreements that are faultless, while the situations in which the dialogue in (4) is used cannot be instances of faultless disagreement. The same applies to the dialogues in (1) and (2): (1) permits faultless disagreements while (2) does not. The present account gives the following explanations. Since the disagreements in (1) and (3) are explained in terms of non-cotenable evaluative attitudes, both $A$ and $B$ may have their respective attitudes without making any mistake: both $A$ and $B$ are right about what they feel with respect to Choco's taste, although their respective attitudes are non-cotenable. On the other hand, the disagreements in (2) and (4) are based on the fact that $A$ and $B$ adhere to incompatible propositions, in which case their disagreements cannot be faultless: if $A$ 's proposition is true (because of correctly describing $A$ 's attitude toward Choco), $B$ 's proposition must be false and vice versa.

Furthermore, this account is in a position to cope satisfactorily with the dialogue in (5). That dialogue jeopardized Gutzmann's theory, according to which the use-conditional content of a taste utterance is connected with its truth-conditional content. The dialogue should be found acceptable, and the present account delivers the right result. $B$ denies that $A$ 's proposition that Choco is tasty for $A$ is true and, in doing so, also denies that $A$ likes the cake's flavor. This rejection of a factual proposition and its consequence is consistent with the normative claim about how people should view the cake's flavor. $B$ 's normative claim about the cake ("However, people should consider it tasty") as well as his descriptive claim about the fact that it lives up to the recommendation ("In fact, I find it delicious") are thus perfectly acceptable. The present account confirms it. The theory does not assign to taste utterances any normative kind of content that would be rejected by rejecting their truth-conditional contents. For this reason, the present account surpasses Gutzmann's.

It is also easy to see that the present explanation provides intuitively acceptable decisions about the dialogues that were used to challenge Buekens's theory. The dialogue in (8) was claimed to be infelicitous. The present account is consistent with this intuition. This is because it does not maintain that if $A$ utters "Choco is tasty," she expresses an invitation or recommendation addressed to her audience or other people. That is why $B$ 's response is 
correctly taken to be inappropriate. The same applies to the dialogue in (10). Since Buekens's theory predicted that the dialogues are acceptable, the present account also surpasses Buekens's.

\section{CONCLUSION}

The taste-expressivist theories analyzed in this paper have problems with accommodating doxastic disagreements about taste in which one speaker expresses her disagreement with another speaker's utterance of a taste sentence that is not explicitly judge-relativized.

According to Clapp's theory, taste utterances of this kind pragmatically express mental states as their content but have no metaphysical truth conditions, which means that they do not express propositions that could be assessed as true or false. If the point of someone's disagreement with the speaker is to accuse the latter of speaking falsely, the account is unable to cope with it. Since it is possible to accuse speakers of lying about their tastes, there definitely are situations (in suitable settings) in which it is plausible to respond to an utterance of "This is tasty" with "That's not true." Clapp's theory cannot handle them.

According to Gutzmann's theory, taste utterances of not explicitly judgerelativized taste sentences have both a truth-conditional and a use-conditional kind of content that is normative at heart. The two kinds of content are linked to each other, so that rejecting the former leads to rejecting the latter as well. It seems, therefore, that this account does not make room for situations in which someone disagrees with the speaker's truth-conditional content but still accepts the normative aspect of her use-conditional content. Since situations of this kind are possible, a theory that predicts their unavailability must be too narrow.

According to Buekens's theory, utterances of taste sentences that are not explicitly judge-relativized express both an assertive (i.e., truth-conditional) and an affective-expressive (i.e., non-truth-conditional) kind of content that is transcendent and consists in inviting others to join the speaker's view. It seems, however, that taste utterances cannot be properly used to invite others to adopt a certain kind of attitude toward something. This is because ordinary ways of rejecting or accepting invitations cannot be used as permissible responses to taste utterances.

The contextualist account outlined in this paper appears to be better off compared to the above theories. On this view, taste utterances express con- 
textually enhanced propositions; they do not express any other kind of content such as mental states, normative content, or affective-expressive content. Yet the account guarantees that by uttering a taste sentence the speaker makes plain the judge's non-doxastic attitudes toward the object of taste. This approach can handle situations in which people express either doxastic or non-doxastic disagreement with what speakers say by uttering not explicitly judge-relativized taste sentences. It thus delivers acceptable results about situations that are troubling for the above accounts.

\section{BIBLIOGRAPHY}

Barker S. (2000), "Is Value Content a Component of Conventional Implicature?," Analysis 6o(3), 268-279. https://doi.org/10.1111/1467-8284.00239

Boisvert D. (2008), "Expressive-Assertivism," Pacific Philosophical Quarterly 89(2), 169203. https://doi.org/10.1111/j.1468-0114.2008.00315.x

Buekens F. (2011), "Faultless Disagreement, Assertions and the Affective-Expressive Dimension of Judgments of Taste," Philosophia 39(4), 637-655. https://doi.org/10.1007 /s11406-011-9318-5

Clapp L. (2015), “A Non-alethic Approach to Faultless Disagreement,” Dialectica 69(4), 517-550. https://doi.org/10.1111/1746-8361.12104

Copp D. (2001), "Realist-Expressivism: A Neglected Option for Modal Realism," Social Philosophy and Policy 18(2), 1-43. https://doi.org/10.1017/So265052500002880

Duží M., Jespersen B., Materna P. (2010), Procedural Semantics for Hyperintensional Logic: Foundations and Applications of Transparent Intensional Logic, Dordrecht: Springer. https://doi.org/10.1007/978-90-481-8812-3

Egan A. (2010), "Disputing about Taste" [in:] Disagreement, R. Feldman, T. A. Warfield (eds.), Oxford: Oxford University Press, 247-286. https://doi.org/10.1093/acprof:oso/ 9780199226078.003.0011

Egan A. (2014), "There's Something Funny about Comedy: A Case Study in Faultless Disagreement," Erkenntnis 79(Supplement 1), 73-100. https://doi.org/10.1007/s10670013-9446-3

Eriksson J. (2014), "Hybrid Expressivism: How to Think about Meaning” [in:] Having It Both Ways: Hybrid Theories and Modern Metaethics, G. Fletcher, M. Ridge (eds.), Oxford: Oxford University Press, 149-170. https://doi.org/10.1093/acprof:oso/97801 99347582.003.0007

Finlay S. (2005), "Value and Implicature," Philosophers' Imprint 5(4), 1-20.

Fletcher G. (2014), "Moral Utterances, Attitude Expressions, and Implicature" [in:] Having It Both Ways: Hybrid Theories and Modern Metaethics, G. Fletcher, M. Ridge (eds.), Oxford: Oxford University Press, 173-198. https://doi.org/10.1093/acprof:oso/97801 99347582.003.0008

Glanzberg M. (2007), “Context, Content, and Relativism,” Philosophical Studies 136(1), 1-29. https://doi.org/10.1007/s11098-007-9145-5 
Gutzmann D. (2016), "If Expressivism Is Fun, Go for It!" [in:] Subjective Meaning: Alternatives to Relativism, C. Meier, J. van Wijnberger-Huitink (eds.), Berlin: de Gruyter, 21-46.

Huvenes T. T. (2012), "Varieties of Disagreement and Predicates of Taste," Australasian Journal of Philosophy 90(1), 167-181. https://doi.org/10.1080/00048402.2010.550305

Karczewska N. (2016), "Disagreements about Taste as Metalinguistic Negotiations - Some Critical Remarks," Filozofia Nauki 24(1) [93], 27-39.

Kölbel M. (2002), Truth without Objectivity, London-New York: Routledge. https://doi.org /10.1111/j.1933-1592.2005.tboo467.x

Lasersohn P. (2005), "Context Dependence, Disagreement, and Predicates of Personal Taste,” Linguistics and Philosophy 28(6), 643-686. https://doi.org/10.1007/s10988005-0596-x

López de Sa D. (2008), "Presuppositions of Commonality: An Indexical Relativist Account of Disagreement” [in:] Relative Truth, M. García-Carpintero, M. Kölbel (eds.), Oxford: Oxford University Press, 297-310. https://doi.org/10.1093/acprof:oso/9780199234950. 003.0014

MacFarlane J. (2014), Assessment Sensitivity: Relative Truth and its Applications, Oxford: Oxford University Press. https://doi.org/10.1093/acprof:oso/9780199682751.001.0001

Marques T. (2015), "Disagreeing in Context," Frontiers in Psychology 6(257), 1-12. https://doi.org/10.3389/fpsyg.2015.00257

Marques T., García-Carpintero M. (2014), "Disagreement about Taste: Commonality Presuppositions and Coordination," Australasian Journal of Philosophy 92(4), 701-723. https://doi.org/10.1080/ooo48402.2014.922592

Recanati F. (2007), Perspectival Thought: A Plea for (Moderate) Relativism, Oxford: Oxford University Press. https://doi.org/10.1093/acprof:oso/9780199230532.001.0001

Richard M. (2008), When Truth Gives Out, Oxford: Oxford University Press. https://doi. org/10.1093/acprof:oso/9780199239955.001.0001

Ridge M. (2009), “Moral Assertion for Expressivists,” Philosophical Issues 19(1), 182-204. https://doi.org/10.1111/j.1533-6077.2009.00166.x

Schaffer J. (2011), "Perspective in Taste Predicate and Epistemic Modals" [in:] Epistemic Modality, A. Egan, B. Weatherson (eds.), Oxford: Oxford University Press, 179-226. https://doi.org/10.1093/acprof:oso/9780199591596.003.0007

Schroeder M. (2010), Noncognitivism in Ethics, London-New York: Routledge. https://doi. org/10.4324/9780203856291

Silk A. (2016), Discourse Contextualism: A Framework for Contextualist Semantics and Pragmatics, Oxford: Oxford University Press. https://doi.org/10.1093/acprof:oso/ 9780198783923.003.0003

Strandberg C. (2012), "A Dual Aspect Account of Moral Language," Philosophy and Phenomenological Research 84(1), 87-122. https://doi.org/10.1111/j.1933-1592.2010.00447.x

Tichý P. (1979), “Existence and God,” The Journal of Philosophy 76(8), 403-420. https:// doi.org/10.2307/2025409

Wright C. (1992), Truth and Objectivity, Cambridge, MA: Harvard University Press.

Zeman D. (2016), "Contextualism and Disagreement about Taste" [in:] Subjective Meaning: Alternatives to Relativism, C. Meier, J. van Wijnberger-Huitink (eds.), Berlin: de Gruyter, 91-104.

Zouhar M. (2018), "Conversations about Taste, Contextualism, and Non-doxastic Attitudes," Philosophical Papers 47(3), 429-46o. https://doi.org/10.1080/05568641.2018. 1450159 